\title{
Kinetics and coagulation performance of snail shell biomass in pharmaceutical Effluent.
}

\author{
V.I Ugonabo, M.C Menkiti, O.D. Onukwuli \\ Department of Chemical Engineering Nnamdi Azikiwe University, Awka, Nigeria
}

\begin{abstract}
Coag-flocculation kinetics and evaluation of a bio-coagulant(snail shell derived coagulant) in pharmaceutical effluent at varying; time, dosage and $\mathrm{pH}$ was investigated at room temperature. A conventional standard Jar test apparatus was employed for the tests, while the bio-coagulant denoted as SSC(snail shell coagulant) was produced following standard method [1-2]. Coagulation kinetics data obtained were fitted into relevant model equations for the determination of coag-flocculation functional parameters. $\tau_{1 / 2}$, reaction order, rate constant, dosage and $\mathrm{pH}$, recorded maximum values at 7.25s, 2, $3 \times 10^{-4} \mathrm{~m}^{3} / \mathrm{kg} . \mathrm{s}, 0.1 \times 10^{-3} \mathrm{~kg} / \mathrm{m}^{3}$ and 13 , respectively. The system achieved maximum efficiency of $90.82 \%$ in alkaline effluent medium. The results obtained affirmed that SSC is a good alternative natural resource for the removal of TDSP from pharmaceutical effluent.
\end{abstract}

Keywords: - Biocoagulant, Coagulation, Pharmaceutical Effluent, Snail Shell.

\section{Introduction}

Over recent years, there has been increase in development and industrialization in many countries and the levels of industrial pollution have been constantly on the increase. Effluent from pharmaceutical industry poses great challenge to the industrial waste treatment systems, due to its complex nature, because there is no single approach or treatment method that can be applied to them [3]. Effluent discharged from pharmaceutical industry can be classified based on the type of pharmaceutical compounds such as antibiotics, prescription and non-prescription pharmaceuticals present in it [4]. These effluents are of great environmental concern due to wide usage. For example, the result of effluent that contains fluoroquinone antibiotics, when discharged to water bodies has led to the ability of bacteria to mutate into strains that are resistant to the widely spread antibiotics paving way for infections that cannot be cured [5].

Many methods of treatment for industrial effluent water have been reported in literature [6-7]. Amongst these methods are neutralization, precipitation, ion exchange, coagulation - flocculation. For high concentration of colloidal and non colloidal turbidity in wastewater the coagulation and flocculation process is recommended for their removal [8]. Coagulation flocculation process is the act of destabilizing stable colloidal particles in wastewater and the aggregation of these particles to form flocs for easy removal [8-9]. The use of Synthetic polyelectrolyte such as (Aluminum Sulphate) etc. has played a very dominant role in coagulation-flocculation process. Due to proven performance in treating wastewater and its lower cost, it is used extensively in drinking water and waste water treatment. However, the coagulation-flocculation performance of alum and the likes has some drawbacks:1. its effectiveness is strongly $\mathrm{pH}$ dependent and finished water may have high residual aluminum concentrations.2. Significant quantities of sludge are produced, complicating handling and dosage procedures and their long term effects on human health are not well understood. To minimize these drawbacks natural polyelectrolyte's, which are extracted from plant or animal matter, can be workable alternative to synthetic polyelectrolyte [10]. Natural polyelectrolyte's are easily available, cost effective biodegradable, and safe to human health with a wider effective dosage range of flocculation for various colloidal suspensions [11].

Against this back drop, an investigation of biodegradable, naturally occurring and available coagulant ( snail shell (SS)) was undertaken. SS is a non toxic, biodegradable polymer with high molecular weight, just like chitosan [12]. In the present investigation, SS was examined in an attempt to remove TDSP from pharmaceutical effluent. Invariably, the after effects problems such as, health challenges and post usage handling posed by the synthetic polyelectrolyte's coagulants can be minimized as well solve the environmental aesthetic problem due to indiscriminate littering of snail shells after using the edible content.

\subsection{Theoretical principles and model description} as [13].

The general model for Brownian coagulation of mono dispersed particles at early stage $(t \leq 30)$, is given

$\mathrm{r}_{\mathrm{k}}=\frac{\mathrm{dn} \mathrm{n}_{\mathrm{k}}}{\mathrm{dt}}=\frac{1}{2} \sum \alpha \beta(\mathrm{Vi}, \mathrm{Vj}) \mathrm{n}_{\mathrm{i}} \mathrm{n}_{\mathrm{j}}-\sum \propto \beta(\mathrm{Vi}, \mathrm{Vj}) \mathrm{n}_{\mathrm{i}} \mathrm{n}_{\mathrm{k}}$ 
Where $\mathrm{r}_{\mathrm{k}}=\frac{\mathrm{dN}_{\mathrm{k}}}{\mathrm{dt}}$ is the rate of change of concentration of particle size $k$ (conc./ time)

Where $\propto$ is the particle collision efficiency (fraction of collisions that result in particle attachment, $\beta$ is the collision function (rate that particles are brought into contact by Brownian, shear, ad differential sedimentation), $\mathrm{n}$ is the particle number concentration in a size interval and $\mathrm{i} j$ are subscripts designating particle size class.

The first term of (1), represents the formation of particle size $\mathrm{K}$ by collision of particle size $\mathrm{i}$ and $\mathrm{j}$. The second term represents the loss of particle size $\mathrm{k}$ by collision with all other particles. The value of $\beta$ for Brownian transport mechanism is given as [13].

$$
\beta_{\mathrm{Br}}=\frac{\mathrm{g}}{\mathrm{a}} \varepsilon_{\mathrm{P}} \frac{\mathrm{K}_{\mathrm{B}} \mathrm{T}}{\eta}
$$

Where $\mathrm{K}_{\mathrm{B}}$ Boltzman's constant $(\mathrm{j} / \mathrm{k})$

$\eta$ - is the viscosity of the fluid (effluent medium)

$\varepsilon_{\mathrm{p}}$ - is collision efficiency

$\mathrm{T}$ - is the absolute temperature $(\mathrm{k})$

The general equation representing aggregation rate of particles is obtained by solving the combination of (1 and 2), analytically to yield.

$$
\frac{d N_{t}}{d t}=K N_{t}^{\propto}
$$

Where $N_{t}$ is the total particle concentration at time t, $N_{t}=\Sigma \eta_{\mathrm{k}}$ (mass/volume)

$\mathrm{K}$ is the $\propto^{\text {th }}$ order coagulation-flocculation constant

$\propto$ is the order of coagulation-flocculation.

And $\mathrm{K}=\frac{1}{2} \beta_{\mathrm{BR}}$

Where $\beta_{\mathrm{BR}}$ is collision factor Brownian transport

Also, $\beta_{\mathrm{BR}}=\varepsilon_{\mathrm{p}} \mathrm{k}_{\mathrm{R}}$

Combining (3, 4 and 5), yields

$\frac{d N_{t}}{d t}=\frac{1}{2} \varepsilon_{\mathrm{p}} k_{R} N_{\mathrm{t}}^{\infty}$

Where $K_{R}$ is the Von smoluchowski rate constant for rapid coagulation [13]

$$
K_{R}=8 \pi R D^{1}
$$

$$
R_{p}=2 \mathrm{a}
$$

Where $\mathrm{D}^{1}$ is particle diffusion coefficient, a is particle radius

From Einstein's equation, particle Diffusion coefficient is given [14-15]

$$
\mathrm{D}^{1}=\frac{\mathrm{K}_{\mathrm{B}} \mathrm{T}}{\mathrm{B}}
$$

Where $\mathrm{B}$ is the friction factor from strokes equation:

$$
\mathrm{B}=6 \pi \eta \mathrm{a}
$$

Where $\eta$ is viscousity of the fluid (coagulating and flocculating effluent medium) combining (6 to 10$)$, gives

$$
-\frac{d N_{t}}{d t}=\frac{4}{a} \varepsilon_{p} \frac{K_{B^{T}}}{\eta} N_{t}{ }^{\infty}
$$


Comparing (3 and 11), show that $\mathrm{k}=\frac{4}{\mathrm{a}} \varepsilon_{p} \frac{{ }_{K_{B}}{ }^{T}}{\eta}$

For perikinetic aggregation $\propto$ Theoretically equals 2 (i.e. $\propto=2$ ) as reported $[14,16,17]$.

From fick's law

$$
\mathrm{J}_{\mathrm{f}}=\mathrm{D} 4 \pi \mathrm{R}_{\mathrm{p}}{ }^{2} \frac{d N_{\mathrm{t}}}{d R}
$$

Where $\mathrm{J}_{\mathrm{f}}$ is flux - number of particles per unit surface entering sphere with radius $\mathrm{r}$

Re-arranging and integrating (13), at initial condition $\mathrm{N}_{\mathrm{t}}=0, \mathrm{R}_{\mathrm{p}}=2 \mathrm{a}$

$\frac{\mathrm{J}_{\mathrm{f}}}{4 \pi \mathrm{D}^{1}} \int_{0}^{\mathrm{R}_{\mathrm{p}}} \frac{\omega R_{D}}{R_{D}}=\int_{N 0}^{N_{\mathrm{t}}} \mathrm{dN}_{\mathrm{t}}$

$\mathrm{J}_{\mathrm{f}}=8 \pi \mathrm{D}^{1} \mathrm{aN}_{\mathrm{o}}$

For central particle of same size undergoing Brownian motion, the initial rate of rapid coagulation flocculation is

$$
-\frac{\mathrm{dN}_{\mathrm{t}}}{\mathrm{dt}}=\mathrm{J}_{\mathrm{f}} \varepsilon_{p} \mathrm{~N}_{\mathrm{o}}
$$

On substitution of (15 into 16), yields

$$
\frac{-\mathrm{dN}}{\mathrm{dt}}=8 \pi \mathrm{aD}^{1} \mathrm{~N}_{\mathrm{o}} \varepsilon_{\mathrm{p}}
$$

On substitution of (9 and 10 into 17), gives

$$
\begin{aligned}
& \frac{-\mathrm{dN}_{\mathrm{t}}}{\mathrm{dt}}=8 \pi \mathrm{a} \mathrm{K}_{\mathrm{B}} \frac{\mathrm{T} \mathrm{N} \mathrm{N}_{\mathrm{o}} \varepsilon_{\mathrm{p}}}{6 \pi \eta \mathrm{a}} \\
& \text { Thus } \\
& \frac{-\frac{\mathrm{dN}}{\mathrm{dt}}}{}=\frac{4}{3} \quad \varepsilon_{\mathrm{p}} \frac{\mathrm{K}_{\mathrm{B}} \mathrm{T} \mathrm{N}_{0}^{2}}{\eta}
\end{aligned}
$$

Similarly at $\mathrm{t}>0$

$$
-\frac{d N_{t}}{d t}=\frac{4}{a} e_{p} \frac{K_{B} T N_{t}^{2}}{\eta}
$$

Hence (20), has confirmed the theoretical value $\propto=2$

For $\propto=2,(3)$, yields

$$
\frac{d N_{t}}{d t}=-\mathrm{KN}_{\mathrm{t}}^{2}
$$

$\mathrm{Re}-$ arranging and integrating (21), yields

$\int_{N_{0}}^{N_{t}} d N_{\mathrm{t}}=-\mathrm{K} \int_{0}^{t} d t$

$$
\mathrm{N}_{\mathrm{t}}^{2}
$$

$\frac{1}{N_{t}}=\mathrm{Kt}+\frac{1}{N_{\sigma}}$

Plot of $\left(\frac{1}{N_{t}}\right)$ Vs.t gives a slope of $\mathrm{K}$ and intercept of $\frac{1}{N_{0}}$ 
Kinetics and coagulation performance of snail shell biomass in pharmaceutical Effluent.

From (23), making $\mathrm{N}_{\mathrm{t}}$ the subject matter yields a relation for the evaluation of coagulation period, $\tau^{1 / 2}$

Thus $\mathrm{N}_{\mathrm{t}}=\frac{\text { No }}{1+\text { No Kt }}$

Similarly, $\quad \mathrm{N}_{\mathrm{t}}=\frac{\mathrm{No}_{\mathrm{o}}}{1+\left(\frac{\mathrm{t}}{N_{\sigma} K}\right)}$

Let $\tau=\left(\frac{1}{N_{\sigma^{K K}}}\right)$

Putting (26 into 25), produces

$$
\mathrm{N}_{\mathrm{t}}=\frac{\mathrm{No}}{1+\left(\frac{\mathrm{t}}{\mathrm{r}}\right)}
$$

$1+\frac{\mathrm{N}_{\mathrm{m}}(\mathrm{t})}{\mathrm{t}_{\mathrm{m}+1}^{\mathrm{N}}}=\frac{\frac{\mathrm{t}}{2}\left(\frac{1}{\mathrm{KN}}\right)^{\mathrm{m}-1}}{\left.2 \overline{\left(\frac{1}{K N_{\circ}}\right)}\right)}$

Let $\tau_{1 / 2}=\tau=\quad \tau^{1}$

(29)

Similarly $\frac{N m(t)}{N_{o}} \frac{\left(t / \tau^{1}\right)^{m-1}}{\left(1+t / \tau^{1}\right)^{m+1}}$

(30), gives a general expression for particle of $\mathrm{m}^{\text {th }}$ order

Where " $m$ " ranges from 1 to 3 for singlets, doublets and triplets respectively.

Evaluation of coagulation - flocculation efficiency is given as

$\mathrm{E}(\%)=\left(\frac{\mathrm{N}_{\mathrm{o}}-\mathrm{N}_{t}}{\mathrm{~N}_{\mathrm{o}}}\right) \times 100$

\section{Materials and method}

2.1 Material sampling, preparation and characterization.

\subsubsection{Pharmaceutical effluent}

The effluent was taken from a pharmaceutical industry located in Awka, Anambra State Nigeria. The characterization of the effluent presented in "TABLE" 1 was determined based on standard method [18].

\subsubsection{Snail Shell Sample}

Snail shell samples (precursor to bio-coagulant) was sourced from Enugwu-Ukwu, Anambra State, Nigeria. Biocoagulant was prepared in line with a reported procedure [1-2].

\subsection{Coagulation-Flocculation Experiment}

Experiments were carried using conventional Jar test apparatus. Appropriate dose of bio-coagulant in the range of $(0.1-0.6) \times 10^{-3} \mathrm{~kg} / \mathrm{m}^{3}$ was added to $250 \mathrm{ml}$ of pharmaceutical effluent. The suspension, tuned to $\mathrm{pH}$ range $1-13$ by addition of $10 \mathrm{M} \mathrm{HCL} / \mathrm{NaOH}$ was subjected to 2 minutes of rapid mixing (120rpm), 20 minutes of slow mixing (10rpm), followed by 30 minutes of settling. During settling, samples were withdrawn from $2 \mathrm{~cm}$ depth and changes in TDSP measured for kinetic analysis (Lab-Tech. Model 212R Turbidimeter) at 
Kinetics and coagulation performance of snail shell biomass in pharmaceutical Effluent.

various time intervals of 2, 4, 6, 1020 and 30 minutes. The whole experiment was carried out at room temperature. The data obtained were subsequently fitted in appropriate kinetic models for evaluation.

\section{TABLE 1: Characteristics of wastewater sample before treatment.}

$\begin{array}{lc}\text { Parameter } & \text { Values } \\ \text { Temperature }\left({ }^{\circ} \mathrm{C}\right) & 27 \\ \text { Electrical Conductivity } \mu \mathrm{S} / \mathrm{cm} & 4.9 \\ \mathrm{pH} & 3.87 \\ \text { phenols }(\mathrm{mg} / \mathrm{l}) & \mathrm{Nil} \\ \text { Odour } & \text { acidic } \\ \text { Total hardness }(\mathrm{mg} / \mathrm{l}) & 6000 \\ \text { Calcium }(\mathrm{mg} / \mathrm{l}) & 594 \\ & \\ \text { Magnesium }(\mathrm{mg} / \mathrm{l}) & 250 \\ \text { Chlorides }(\mathrm{mg} / \mathrm{l}) & 100 \\ \text { Dissolved oxygen (mg/l) } & 20 \\ \text { Biochemical Oxygen Demand }(\mathrm{mg} / \mathrm{l}) & 5 \\ \text { Chemical Oxygen Demand }(\mathrm{mg} / \mathrm{l}) & 1.00 \\ \text { Turbidity }(\mathrm{NTU}) & 128 \\ \text { Iron mg/l } & \mathrm{Nil} \\ \text { nitrate mg/l } & \mathrm{Nil} \\ \text { Total acidity (mg/l) } & 250 \\ \text { Total viable count }(\mathrm{cfu} / \mathrm{ml}) & 9 \times 10^{1} \\ \text { Total coliform MPN/100ml } & \mathrm{Nil} \\ \text { Total Coliform count cfu/ml } & 1 \times 10^{1} \\ \text { Faecal count MPN/ml } & \mathrm{Nil} \\ \text { Clostridium perfrigens MPN/ml } & \mathrm{Nil}\end{array}$

TABLE 2: Coagulation-Flocculation functional parameters for varying $\mathrm{pH}$ and constant dosage of $0.1 \times 10^{-}$ ${ }^{3} \mathrm{~kg} / \mathrm{m}^{3}$

$\begin{array}{lllllll}\text { Parameter } & \mathrm{pH}=1 & \mathrm{pH}=3 & \mathrm{pH}=5 & \mathrm{pH}=7 & \mathrm{pH}=10 & \mathrm{pH}=13 \\ \alpha & 2 & 2 & 2 & 2 & 2 & 2 \\ R^{2} & 0.328 & 0.328 & 0.524 & 0.964 & 0.839 & 0.636 \\ K\left(m^{\mathrm{a}} / \mathrm{kg} . \mathrm{S}\right) & 2 \times 10^{-4} & 5 \times 10^{-6} & 5 \times 10^{-6} & 9 \times 10^{-5} & 1 \times 10^{-4} & 1 \times 10^{-4} \\ \beta_{B r}\left(\mathrm{~m}^{\mathrm{a}} / \mathrm{kg} . \mathrm{S}\right) & 4 \times 10^{-4} & 1 \times 10^{-5} & 1 \times 10^{-5} & 1.8 \times 10^{-4} & 2 \times 10^{-4} & 2 \times 10^{-4} \\ K_{R}\left(\mathrm{~m}^{\mathrm{a}} / \mathrm{S}\right) & 1.529 \times 10^{-19} & 1.549 \times 10^{-19} & 1.586 \times 10^{-1} & 1.539 \times 10^{-19} & 1.555 \times 10^{-19} & 1.560 \times 10^{-19} \\ \varepsilon_{\mathrm{p}}\left(\mathrm{kg}^{-1}\right) & 2.616 \times 10^{15} & 6.456 \times 10^{13} & 6.305 \times 10^{13} & 1.170 \times 10^{15} & 1.286 \times 10^{15} & 1.282 \times 10^{15} \\ \tau_{2}^{1}(\mathrm{~S}) & 10.87 & 289.86 & 217.39 & 16.10 & 14.49 & 9.66\end{array}$

TABLE 3: Coagulation-Flocculation functional parameters for varying $\mathrm{pH}$ and constant dosage of $0.2 \times 10^{-}$ ${ }^{3} \mathrm{~kg} / \mathrm{m}^{3}$

$\begin{array}{llllll}\begin{array}{l}\text { Parameter } \\ \mathrm{pH}=13\end{array} & \mathrm{pH}=1 & \mathrm{pH}=3 & \mathrm{pH}=5 & \mathrm{pH}=7 & \mathrm{pH}=10 \\ \alpha & 2 & 2 & 2 & 2 & 2 \\ 2 & 2 & 0.924 & 0.102 & 0.929 & 0.865 \\ R^{2} & 0.762 & 8 \times 10^{-6} & 4 \times 10^{-6} & 1 \times 10^{-4} & 9 \times 10^{-5} \\ 0.651 & 8 \times 10^{-5} & 1.6 \times 10^{-5} & 8 \times 10^{-6} & 2 . \times 10^{-4} & 1.8 \times 10^{-4} \\ K\left(m^{\mathrm{a}} / \mathrm{kg} . \mathrm{S}\right) & & & & \\ 1 \times 10^{-4} & 1.6 \times 10^{-4} & & & & \\ \beta_{B r}\left(m^{\mathrm{a}} / \mathrm{kg} . \mathrm{S}\right) & 1.5319 \times 10^{-19} & & & & \\ 2 \times 10^{-4} & & & & & \end{array}$


Kinetics and coagulation performance of snail shell biomass in pharmaceutical Effluent.

$\begin{array}{llllll}\varepsilon_{p}\left(\mathrm{~kg}^{-1}\right) & 1.045 \times 10^{15} & 1.033 \times 10^{14} & 5.044 \times 10^{13} & 1.30 \times 10^{15} & 1.158 \times 10^{15} \\ 1.282 \times 10^{15} & & & & & \\ \tau_{2}^{2}(\mathrm{~S}) & 27.17 & 181.16 & 271.74 & 14.49 & 16.10 \\ 9.66 & & & & & \end{array}$

TABLE 4: Coagulation-Flocculation functional parameters for varying $\mathrm{pH}$ and constant dosage of $0.3 \times 10^{-}$ ${ }^{3} \mathrm{~kg} / \mathrm{m}^{3}$

\begin{tabular}{|c|c|c|c|c|c|}
\hline $\begin{array}{l}\text { Parameter } \\
\mathrm{pH}=13\end{array}$ & $\mathrm{pH}=1$ & $\mathrm{pH}=3$ & $\mathrm{pH}=5$ & $\mathrm{pH}=7$ & $\mathrm{pH}=10$ \\
\hline $\begin{array}{l}\alpha \\
2\end{array}$ & 2 & 2 & 2 & 2 & 2 \\
\hline$R^{2}$ & 0.665 & 0.340 & 0.437 & 0.918 & 0.882 \\
\hline $\begin{array}{l}0.627 \\
\mathrm{~K}^{\left(m^{\mathrm{a}} / \mathrm{kg} . \mathrm{S}\right)}\end{array}$ & $3 \times 10^{-4}$ & $8 \times 10^{-6}$ & $3 \times 10^{-6}$ & $9 \times 10^{-5}$ & $6 \times 10^{-5}$ \\
\hline $\begin{array}{l}5 \times 10^{-5} \\
\beta_{B r}\left(m^{3} / \mathrm{kg} . \mathrm{S}\right) \\
1 \times 10^{-4}\end{array}$ & $6 \times 10^{-4}$ & $1.6 \times 10^{-5}$ & $6 \times 10^{-6}$ & $1.8 \times 10^{-4}$ & $1.2 \times 10^{-4}$ \\
\hline $\begin{array}{l}1 \times 10^{-4} \\
K_{R}\left(m^{\mathrm{a}} / \mathrm{S}\right) \\
1.560 \times 10^{-19}\end{array}$ & $1.531 \times 10^{-19}$ & $1.549 \times 10^{-19}$ & $1.586 \times 10^{-19}$ & $1.542 \times 10^{-19}$ & $1.555 \times 10^{-19}$ \\
\hline $\begin{array}{l}\varepsilon_{p}\left(\mathrm{~kg}^{-1}\right) \\
6.410 \times 10^{14}\end{array}$ & $3.919 \times 10^{15}$ & $1.033 \times 10^{14}$ & $3.783 \times 10^{13}$ & $1.167 \times 10^{15}$ & $7.717 \times 10^{15}$ \\
\hline$\tau_{2}^{l}(\mathrm{~S})$ & 7.25 & 181.16 & 362.32 & 16.10 & 24.15 \\
\hline
\end{tabular}

19.32

TABLE 5: Coagulation-Flocculation functional parameters for varying $\mathrm{pH}$ and constant dosage of $0.4 \times 10^{-}$

\begin{tabular}{|c|c|c|c|c|c|c|}
\hline Parameter & $\mathrm{pH}=1$ & $\mathrm{pH}=3$ & $\mathrm{pH}=5$ & $\mathrm{pH}=7$ & $\mathrm{pH}=10$ & $\mathrm{pH}=13$ \\
\hline$\alpha$ & 2 & 2 & 2 & 2 & 2 & 2 \\
\hline$R^{2}$ & 0.690 & 0.017 & 0.236 & 0.983 & 0.925 & 0.960 \\
\hline $\mathrm{K}^{\left(m^{\mathrm{a}} / \mathrm{kg} . \mathrm{S}\right)}$ & $2 \times 10^{-4}$ & $1 \times 10^{-6}$ & $6 \times 10^{-6}$ & $6 \times 10^{-5}$ & $5 \times 10^{-5}$ & $3 \times 10^{-5}$ \\
\hline$\beta_{B r}\left(m^{\mathrm{a}} / \mathrm{kg} . \mathrm{S}\right)$ & $4 \times 10^{-4}$ & $2 \times 10^{-6}$ & $1.2 \times 10^{-5}$ & $1.2 . \times 10^{-4}$ & $1 \times 10^{-4}$ & $6 \times 10^{-5}$ \\
\hline$K_{R}\left(m^{a} / S\right)$ & $1.534 \times 10^{-19}$ & $1.549 \times 10^{-19}$ & $1.587 \times 10^{-19}$ & $1.542 \times 10^{-19}$ & $1.557 \times 10^{-19}$ & $1.562 \times 10^{-19}$ \\
\hline$\varepsilon_{p}\left(\mathrm{~kg}^{-1}\right)$ & $2.608 \times 10^{15}$ & $1.291 \times 10^{13}$ & $7.561 \times 10^{13}$ & $7.782 \times 10^{14}$ & $6.423 \times 10^{14}$ & $3.841 \times 10^{14}$ \\
\hline$\tau_{2}^{d}(S)$ & 10.87 & 1449.28 & 181.16 & 24.15 & 28.99 & 32.21 \\
\hline
\end{tabular}

TABLE 6: Coagulation-Flocculation functional parameters for varying $\mathrm{pH}$ and constant dosage of $0.5 \times 10^{-}$ ${ }^{3} \mathrm{~kg} / \mathrm{m}^{3}$

$\begin{array}{llllll}\begin{array}{l}\text { Parameter } \\ \mathrm{pH}=13\end{array} & \mathrm{pH}=1 & \mathrm{pH}=3 & \mathrm{pH}=5 & \mathrm{pH}=7 & \mathrm{pH}=10 \\ \alpha & 2 & 2 & 2 & 2 & 2 \\ 2 & 2 & 0.995 & 0.656 & 0.976 & 0.911 \\ R^{2} & 0.836 & 7 \times 10^{-6} & 3 \times 10^{-6} & 9 \times 10^{-5} & 8 \times 10^{-5} \\ \begin{array}{l}0.840 \\ \mathrm{~K}\left(\mathrm{~m}^{\mathrm{a}} / \mathrm{kg} . \mathrm{S}\right)\end{array} & 4 \times 10^{-5} & 1.4 \times 10^{-6} & 6 \times 10^{-6} & 1.8 \times 10^{-4} & 1.6 \times 10^{-4} \\ 4 \times 10^{-5} & & & & & \\ \beta_{\text {Br }}\left(\mathrm{m}^{\mathrm{a}} / \mathrm{kg} . \mathrm{S}\right) & 8 \times 10^{-5} & 1.550 \times 10^{-19} & 1.587 \times 10^{-19} & 1.542 \times 10^{-19} & 1.557 \times 10^{-19} \\ 8 \times 10^{-5} & 1.534 \times 10^{-19} & & & & \\ K_{R}\left(m^{\mathrm{a}} / \mathrm{S}\right) & 5.215 \times 10^{14} & 9.032 \times 10^{12} & 3.781 \times 10^{13} & 1.167 \times 10^{15} & 1.028 \times 10^{15} \\ \begin{array}{l}1.562 \times 10^{-19} \\ \varepsilon_{\mathrm{p}}\left(\mathrm{kg}^{-1}\right)\end{array} & & & & & \\ 5.122 \times 10^{14} & & & & \end{array}$


Kinetics and coagulation performance of snail shell biomass in pharmaceutical Effluent.

$\begin{array}{llllll}\tau_{2}^{l}(\mathrm{~S}) & 54.35 & 207.04 & 362.32 & 16.10 & 18.12\end{array}$

24.15

TABLE 7: Coagulation-Flocculation functional parameters for varying $\mathrm{pH}$ and constant dosage of $0.6 \times 10^{-}$ ${ }^{3} \mathrm{~kg} / \mathrm{m}^{3}$

Parameter

$\mathrm{pH}=13$

$\alpha$

2

$R^{2}$

$\mathrm{pH}=1$

$\mathrm{pH}=3$

$\mathrm{pH}=5$

$\mathrm{pH}=7$

$\mathrm{pH}=10$

2

2

2

2

2

0.731

$\mathrm{K}^{\left(m^{\mathrm{a}} / \mathrm{kg} . \mathrm{S}\right)}$

0.673

0.995

0.934

0.960

0.914

$3 \times 10^{-6}$

$\beta$ Br $\left(m^{3} / \mathrm{kg} . \mathrm{S}\right)$

$2 \times 10^{-4}$

$5 \times 10^{-6}$

$7 \times 10^{-7}$

$7 \times 10^{-5}$

$5 \times 10^{-5}$

$K_{R}\left(m^{a} / \mathrm{S}\right)$

$4 \times 10^{-4}$

$1 . \times 10^{-5}$

$1.4 \times 10^{-5}$

1.4. $\times 10^{-4}$

$1 \times 10^{-4}$

$1.562 \times 10^{-19}$

$\varepsilon_{\mathrm{p}}\left(\mathrm{kg}^{-1}\right)$

$1.537 \times 10^{-19}$

$1.550 \times 10^{-19}$

$1.587 \times 10^{-19}$

$1.542 \times 10^{-19}$

$1.557 \times 10^{-19}$

$3.841 \times 10^{13}$

$\tau_{2}^{l}(\mathrm{~S})$

$2.602 \times 10^{15}$

$6.452 \times 10^{13}$

$8.822 \times 10^{13}$

$9.079 \times 10^{14}$

$6.423 \times 10^{14}$

322.06

10.87

289.87

362.32

20.70

28.99

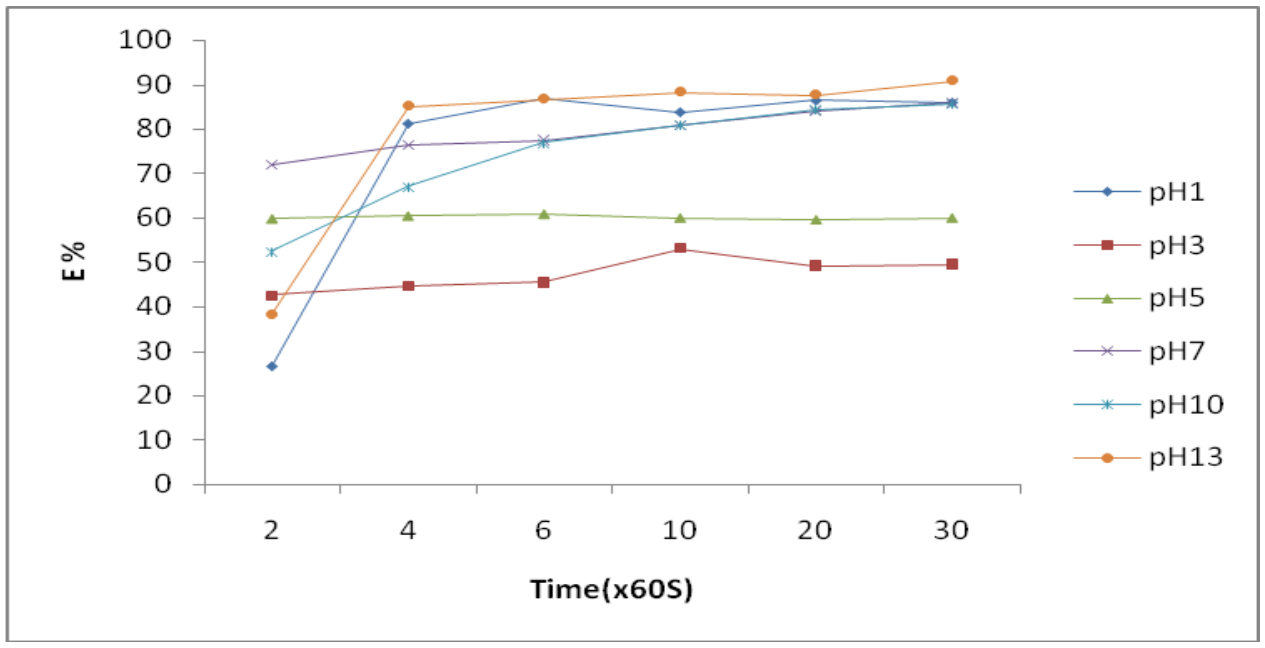

"Fig". 1. Representative Plot of E\% VS Coag-flocculation time at varying $\mathrm{pH}$ and constant dosage of $0.1 \times 10-3$ $\mathrm{kg} / \mathrm{m} 3$ 
Kinetics and coagulation performance of snail shell biomass in pharmaceutical Effluent.

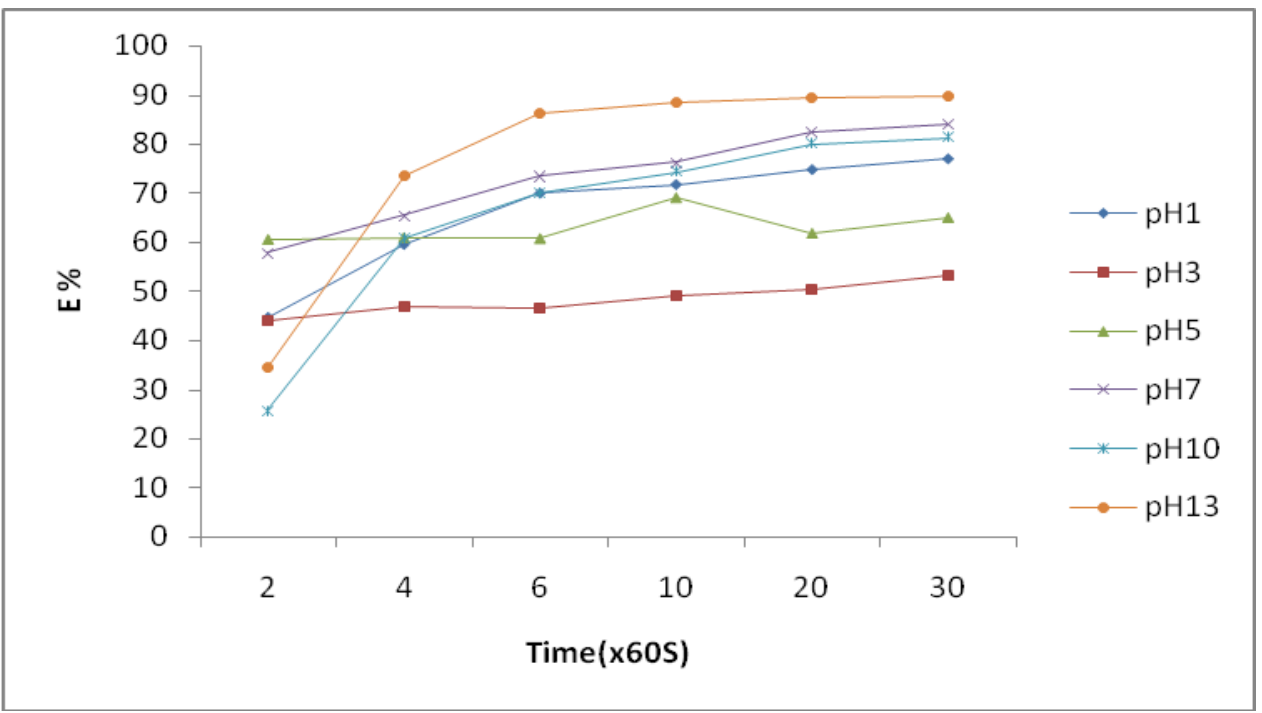

"Fig." 2. Representative Plot of E\% VS Coag-flocculation time at varying $\mathrm{pH}$ and constant dosage of $0.2 \times 10-3$ $\mathrm{kg} / \mathrm{m} 3$

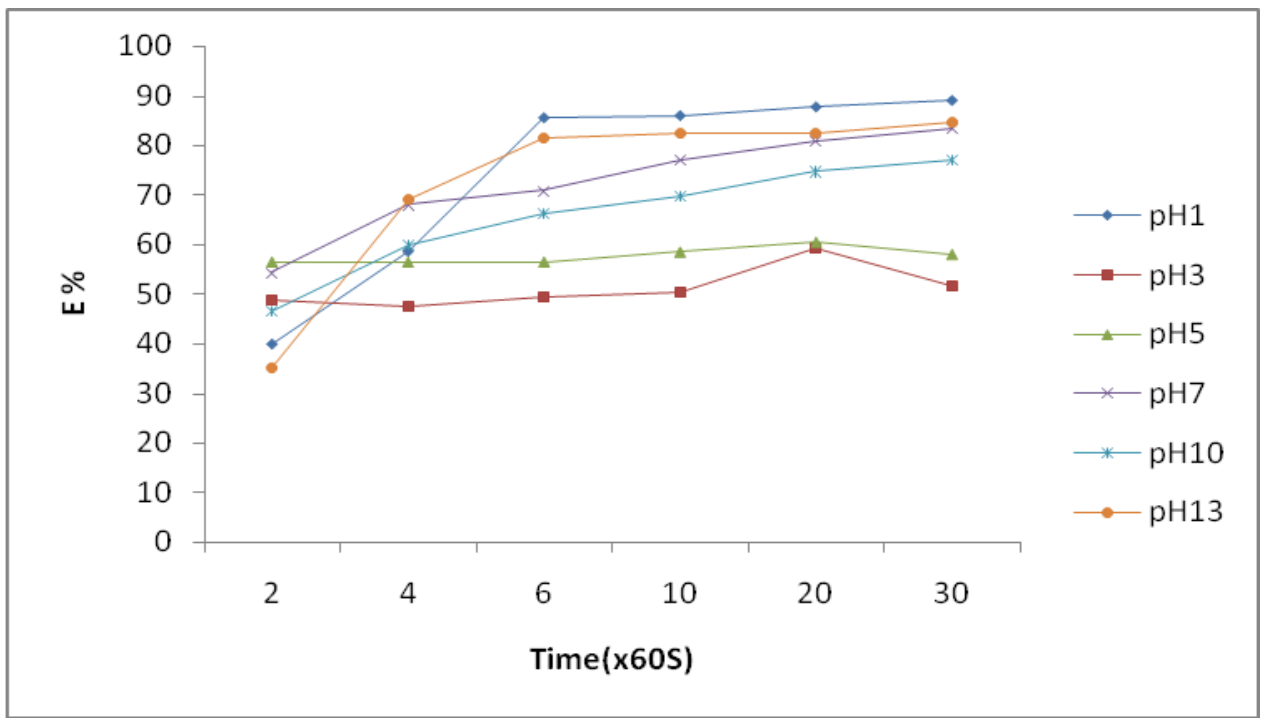

"Fig"3. Representative Plot of E\% VS Coag-flocculation time at varying $\mathrm{pH}$ and constant dosage of $0.3 \times 10-3$

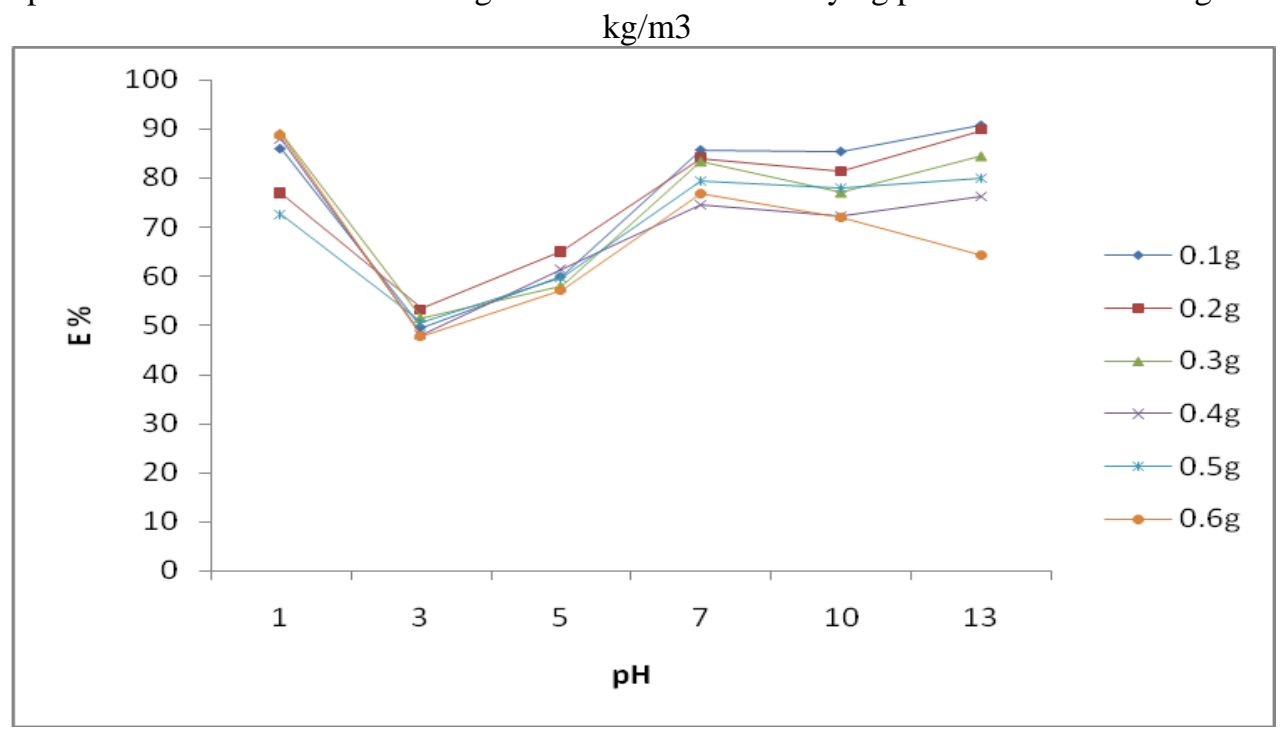

"Fig." 4: Plot of E\% VS pH at varying dosage 
Kinetics and coagulation performance of snail shell biomass in pharmaceutical Effluent.

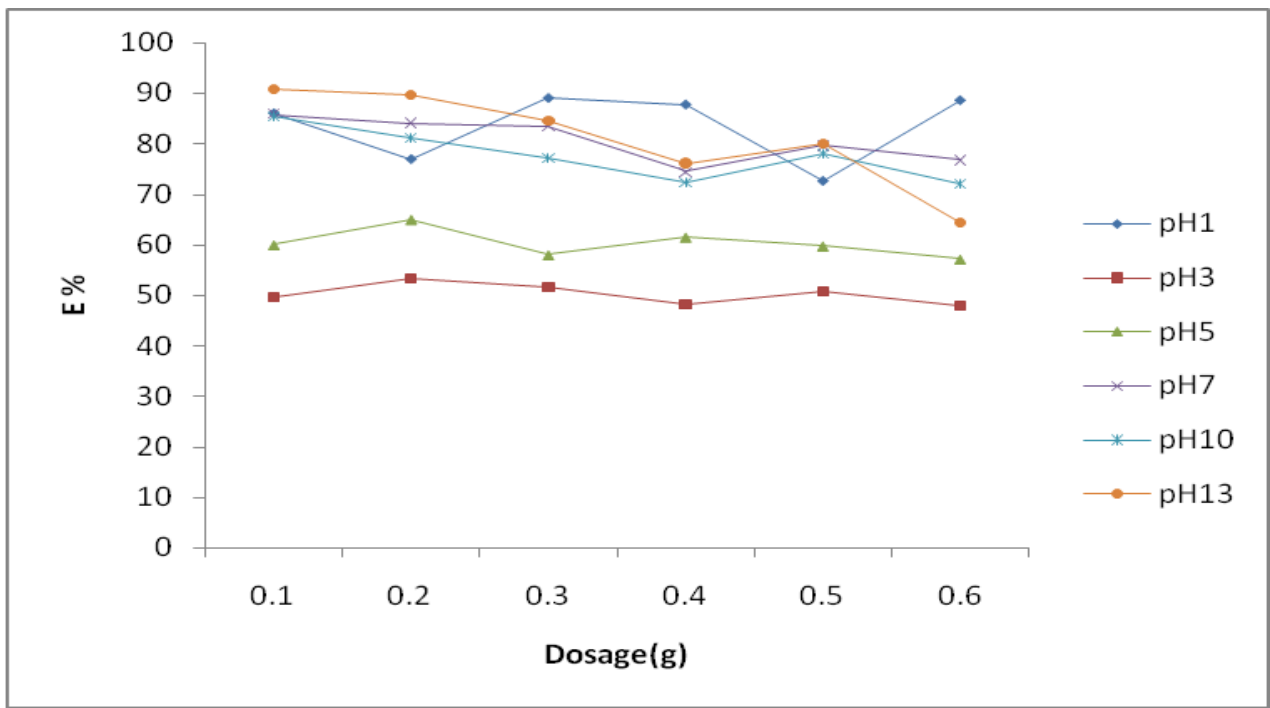

"Fig."5.Plot of E\% VS dosage at varying $\mathrm{pH}$

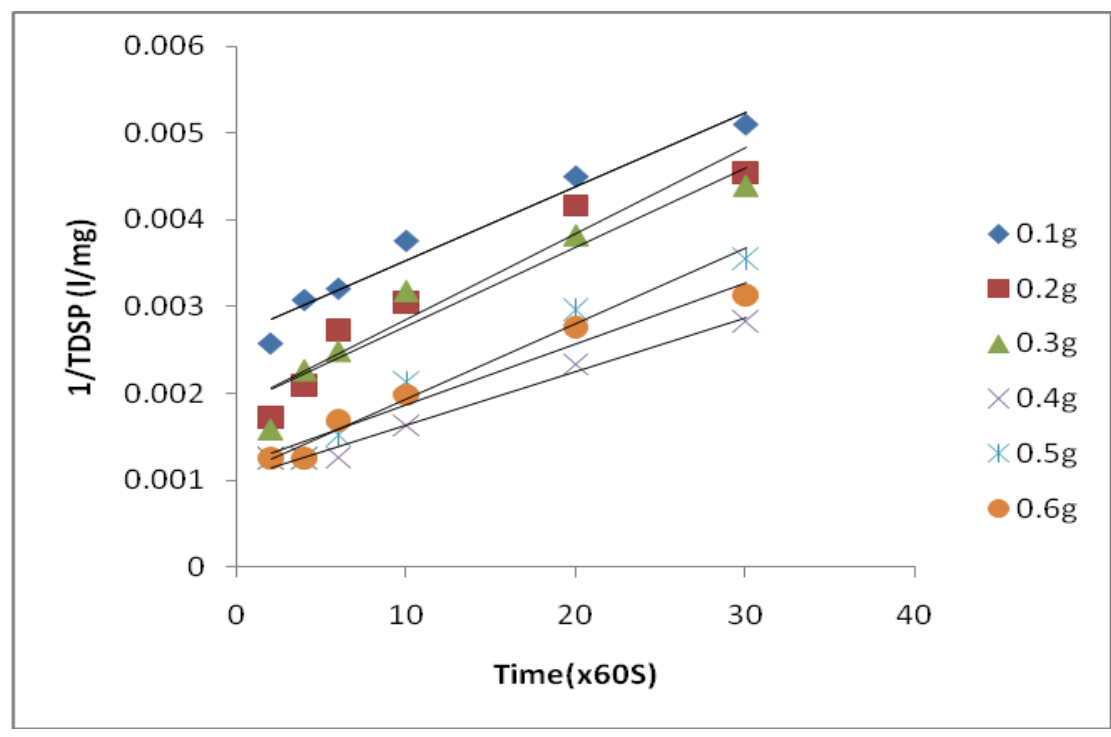

"Fig" 6. Representative Plot of 1/TDSP VS Coag-flocculation time at constant $\mathrm{pH}=7$ and varying dosage (Experimental initial concentration No $=1380 \mathrm{mg} / \mathrm{l})$

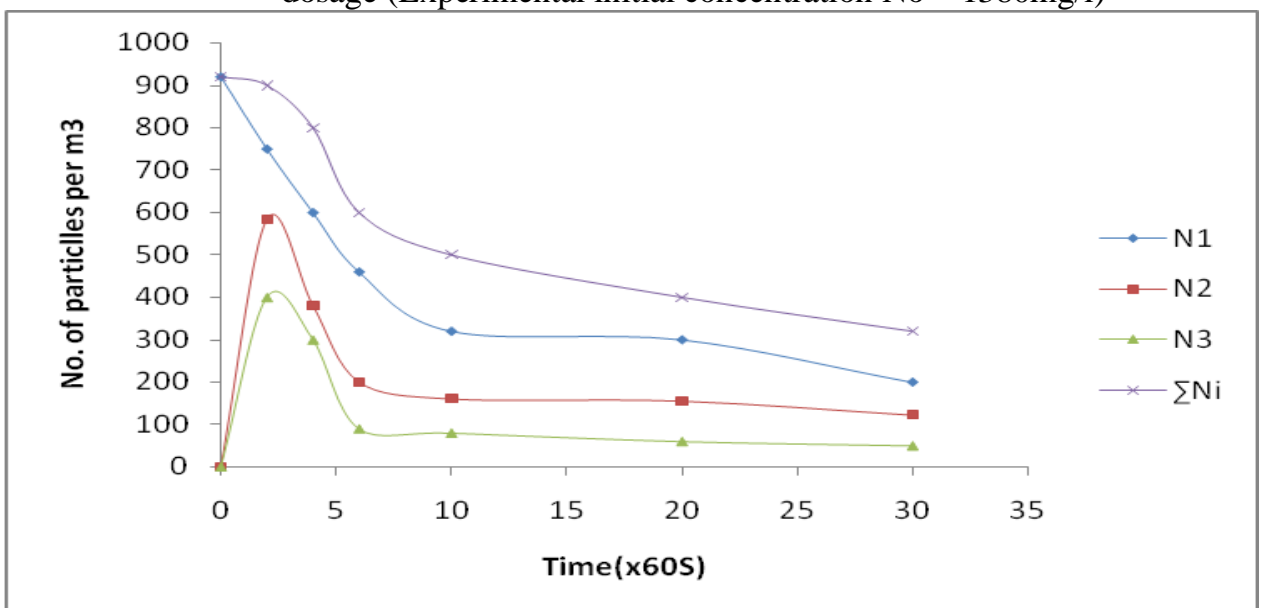

Figure 7:Representative plot of microscopic particle size distribution for half life 7.25S 
Kinetics and coagulation performance of snail shell biomass in pharmaceutical Effluent.

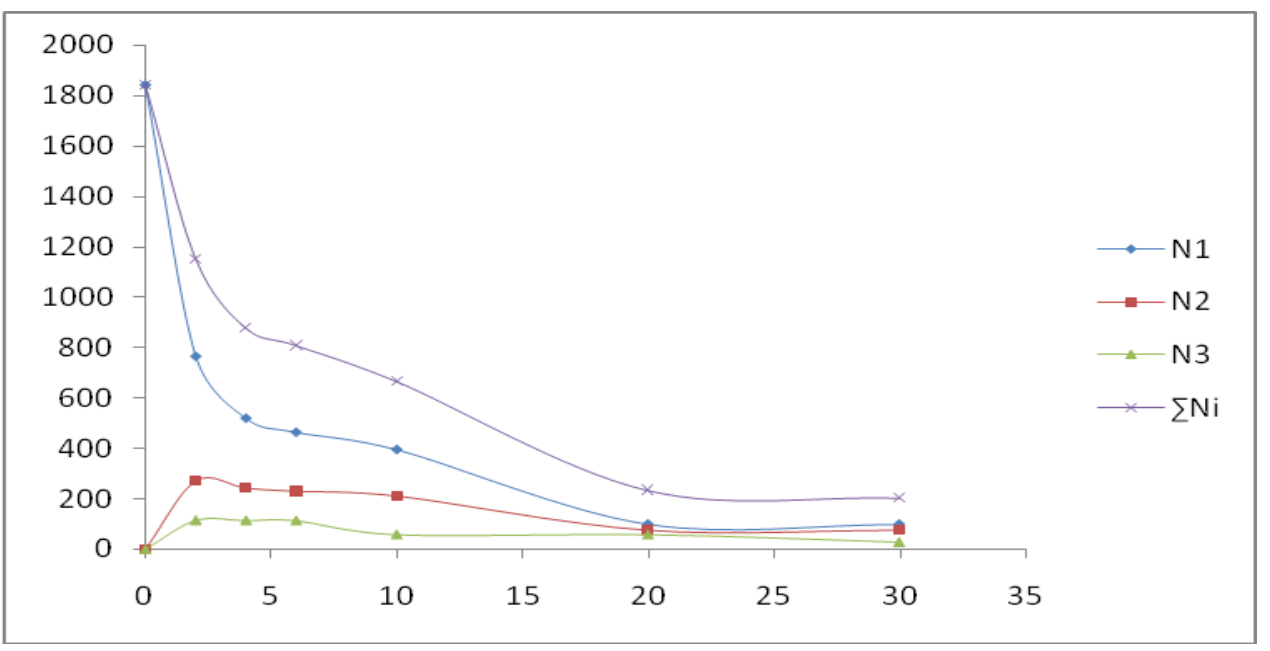

Figure 8 : Representative plot of microscopic particle size distribution for half life of $1552.80 \mathrm{~S}$

\section{Results and Discussion}

\subsection{Variation of SSC Removal Efficiency, $\mathrm{E}(\%)$ as a function of Time, $\mathrm{pH}$ and Dosage}

The variation of removal efficiency $\mathrm{E}(\%)$ with time, $\mathrm{pH}$ and dosage is obtained based on the evaluation of (31). Selected plots of the results presented in "figs". $1-5$ are obtained at $(0.1,0.2,0.3,0.4,0.5,0.6) \times 10^{-3}$ $\mathrm{kg} / \mathrm{m}^{3} \mathrm{SSC}$ dosage for $\mathrm{pH} 1,3,5,7,10,13$. The general observable coag-flocculation behaviour in "figs".1-5, show that efficiency increases with time, but the magnitude varies for different $\mathrm{pH}$ and dosage. The efficiency at 2 minutes was generally, between 60.43 and $64.35 \%$ at $\mathrm{pH}=5$ and 1 , respectively. Considering "figs". $1-5$, it can be observed that at 30 minutes of coagulation - flocculation, the least efficiency value obtained is more than $47 \%$. This is an indication that at least 47 and $60.43 \%$ of initial TDSP load of $1380 \mathrm{mg} / \mathrm{l}$ were removed at 2 and 30 minutes, respectively. SSC best performance is achieved at $\mathrm{pH}=13$ of $0.1 \times 10^{-3} \mathrm{~kg} / \mathrm{m}^{3}$. The $\mathrm{pH}$ is controlled by adding either strong acid (HCL) or strong base $(\mathrm{NaOH})$. The good performance at alkaline condition as observed is expected presumably due to adsorption of TDSP in the effluent onto hydroxide flocs. This result is in agreement with previous works [19-20]. This condition is more prevalent in a system dominated by charge neutralization mechanism. Dosage is one of the most important parameters that was considered to have influence on the mechanism of coag-flocculation. From the "figs".1-5, it was observed that, the trends for all parameters were almost identical but with different efficiency (E\%) for the optimum SSC dosage of $0.1 \times 10^{-3}$ $\mathrm{kg} / \mathrm{m}^{3}$, the best efficiency is achieved at $90.82 \%$. This phenomenon could be explained based on charge density principle [21]. Furthermore, the charge density of the SSC increased when SSC adsorption increased [22]. This implies rapid destabilization of the particles. Also, it is observed that there is a drop in the efficiency value when the SSC dosage increases. This poor performance is attributed to excess SSC adsorbtion on the colloidal surfaces and producing restabilized colloids. Hence there were no sites available on the particles surfaces for the formation of interparticle bridges. The restabilized colloidal particles can become positively charged and cause the electrostatic repulsion among the TDSP.

\subsection{Turbidmetric Kinetic Results:}

The kinetic tests were performed using the photometric Dispersion Analyser, for a sample of pharmaceutical effluent with an initial TDSP of $1380 \mathrm{mg} / \mathrm{l}$, SSC dosage of $(0.1,0.2,0.3,0.4,0.5,0.6) \times 10^{-3}$ $\mathrm{kg} / \mathrm{m}^{3}$ and $\mathrm{pH}(1,3,5,7,10,13)$. The results obtained from the analysis were evaluated as the coag-flocculation functional parameters which are presented in "TABLES" 2-7.

Solving (21), by integration method (taking $\propto=2$ ), yields (23), presented in the selected plot, "fig".6. $\mathrm{K}$ is obtained from the plots as the slope of $1 / \mathrm{Nt}$ Vs t plot. The experimental data were fitted into the generalized model represented as (23), using linear regression coefficient $\left(\mathrm{R}^{2}\right)$ to evaluate the degree of accuracy. Results in "TABLES" 2-7 show that majority of $\mathrm{R}^{2}$ values are high, which indicates a high measure of agreement that the reaction is a second order with various constant. This phenomenon, show that the rate of reaction is proportional to $\mathrm{N}_{\mathrm{t}}$ and $\mathrm{K}$ as described by (21). $\mathrm{K}$ values posted in "TABLES" 2-7, can also be evaluated from (4) $\mathrm{k}=0.5 \beta_{\mathrm{BR}}$, if the collision coefficient due to Brownian motion $\left(\beta_{\mathrm{BR}}\right)$ is known. The highest value of $\mathrm{k}$ is $3 \times 10^{-4} \mathrm{~m}^{3} / \mathrm{kg}$.S recorded at $\mathrm{pH}=1$ and $0.3 \times 10^{-3} \mathrm{~kg} / \mathrm{m}^{3}$. SSC, while the least is $7 \times 10^{-7} \mathrm{~m}^{3} / \mathrm{kg} . \mathrm{S} \mathrm{SSC}$. Critical observation of "figs".1-5, show that best performances at the conditions of these experiments were achieved at alkaline medium with a lower SSC dosage, which is preferred in treatment process. It can be deduced from the 
Kinetics and coagulation performance of snail shell biomass in pharmaceutical Effluent.

observation, that coag-flocculation with low dosage is more favoured in alkaline medium based on the charge density principle [21].

$\tau_{1 / 2}, \varepsilon_{\mathrm{p}}$ and $\mathrm{K}_{\mathrm{R}}$ are particle coagulation effectiveness factors, known to be responsible for the coagulation efficiency before particle aggregation [20]. $\tau_{I / 2}$ actually indicates the time taken for the initial concentration of TDSP to reduce by half, evaluated from (26). It also serves as a measure for the rate of coagflocculation process. Low period is a condition for fast rate of aggregation, which is desirable in process design. Critical observation of (26) show that $\tau_{I / 2}$ is a function of initial TDSP $\left(\mathrm{N}_{\mathrm{o}}\right)$ concentration and rate constant $\mathrm{K}$. The Mathematical implication of (26) is that the higher the $\mathrm{N}_{\mathrm{o}}$, the lesser the $\tau_{I / 2}$. In this study, it is observed that lowest $\tau_{I / 2}(7.25 \mathrm{~S})$ is recorded at high $\mathrm{k} 3 \times 10^{-3} \mathrm{~kg} / \mathrm{m}^{3}$. This high $\mathrm{k}$ is a condition for low $\tau_{I / 2}$.

$\varepsilon_{\mathrm{p}}$, which is particle collision efficiency relates proportionally to the kinetic energy acquired by the colliding particles. High $\varepsilon_{\mathrm{p}}$, results in high kinetic energy required to overcome additional repulsive forces caused, for instance by electrostatic interactions, that hinders particles from aggregating.

$K_{R}$, is related to Boltzman constant $K_{B}$, temperature $T$, and viscousity of the fluid, $\eta$. Combining ( 7, 9 , 10), show that $K_{R}$ is proportionally related to $K_{B}$ and $T$ and inversely with $\eta$. The minimal variations of $K_{R}$ posted in "TABLES" $2-7$ were attributed to constant $K_{B}$ and $\eta$ and minimal variant in temperature values employed in this study.

\subsection{Microscopic particle distribution behavior.}

On substitution of $\tau_{I / 2}$ values from (26 and 29) into (30), the following microscopic particle agglomeration behavior were evaluated and presented in the selected plots, "figs". 7-8. Thus ( 30 ), specifically represents the particle concentration of monomers, doublets and triplets as a function of time; where $\mathrm{N}_{\mathrm{o}}$, stands for initial particle concentration (TDSP) and $\mathrm{N}_{1}, \mathrm{~N}_{2}, \mathrm{~N}_{3}$, stands for final particle concentration for monomers, doublets, triplets respectively. It has been shown by experiment that (30), describe particle concentrations at the early stage of coag-flocculation process quite well [23]. The selected plots in "figs.". 7-8, actually depicts the responses of (30) to two different $\tau_{I / 2}$ of $7.25 \mathrm{~S}$ and $1552.80 \mathrm{~S}$.

"Fig".7, show a particle distribution curves that has features of a system being controlled by rapid colloidal destabilization mechanism. In this case, the particles (monomers, doublets and triplets) are seen decreasing linearly with time until it gets to a point, where the coagulation rate attains the maximum value, which does not change any more with further increasing electrolyte (SSC) concentration, minimum $\tau_{I / 2}$ value is recorded (7.25S) corresponding to the half - period of rapid coagulation. This assertion is in agreement with previous work [24]. Also in "fig".7, there are forces of repulsion and attraction between the approaching particles. These are electrostatic repulsion between the monomers and the sum of the particle which leads to van der waals attraction of its dispersion component. The repulsion is an exponential, whereas the attraction is a hyperbolic function of the distance [24]. Above all, attraction appears to be more dominant as seen in "fig".7. "Fig".8, depicts the distribution of particles profile where there is slow colloidal destabilization regime, resulting to low particle entrapment and low bridging mechanism. This phenomenon, is an indication that there is no particle sweep, only a fraction of particle collisions are successful. This is supported by period of $1552.80 \mathrm{~S}$, which is very high for most effluent treatment operations.

\section{Conclusion}

Under the conditions of the experiment, the evaluation on the effectiveness and efficiency of SSC for the removal of TDSP in pharmaceutical effluent by coag-flocculation has been carried out. The value of the percentage of TDSP removed from pharmaceutical effluent after 30 minutes is $1253.32 \mathrm{mg} / \mathrm{l}$. The system achieved maximum efficiency of $90.82 \%$ at $0.1 \times 10^{-3} \mathrm{~kg} / \mathrm{m}^{3}$ and $\mathrm{pH}=13$, an indication that the system operates best under alkaline medium. Moreover, the system attains maximum coagulation rate at a minimum $\tau_{I / 2}(7.25 \mathrm{~S})$. The results obtained are in agreement with previous works $[14,20,25]$.

\section{References}

[1] M.V., Vaidya, K.R., Bulusu, Chitosan as coagulant and coagulant Aid. IE.J. Environment,1984,(64).43 - 48.

[2] R. Divakaran, V. N., Pillai, Flocculation of River Silt using chitosan, Water Res. (35),2002, $2414-2418$.

[3] S.K., Gupta, S.K., Gupta, Treatment of Pharmaceutical wastes, Indian Institute of Technology, Bombay, India,2006, 167 - 233.

[4] V. Roth,Z. Dong, D.Senn, M. Maclead, J. Shine, Transport and Fate of selected priority pharmaceuticals in U.S. Havard University, Boston, Management USA, SWISS Federal Institute of Technology, Zurich, Switzer Land, 2005, (ROT - 117 - 844293.

[5] Benotti and Etho, Pharmaceutical as tracers of municipal wastewater in Urban Estuaries,2008, (BEN - 117 - 831465)

[6] K. Periasany, C. Namasivayam, The process development for removal and recovery acids from waste water by low cost adsorbent. Sci. Tech. 1995,30.

[7] S.V. Dimitrova, D. R. Mehandgiev, Lead removal from aqueous solution by granulated blast - furnace slag, Water Res. 32 (11), $1998,3289-3292$ 
Kinetics and coagulation performance of snail shell biomass in pharmaceutical Effluent.

[8] A. K. Ghebremichael, Moringa seed and Pumice as alternative natural materials for drinking water treatment TRITA LWR PHD 1013 KTH land and water Resources Engineering,2004.

[9] J.E. Gregor, C.J. Nokes, E. Fenton, Optimizing natural organic matter removal from low turbidity waters by controlled pH adjustment of aluminum coagulant. Water Res., 31(12),1997, $2949-2958$.

[10] V.A., Joshi, M.V. Nanoti, Lab studies on Tarota as coagulant aid in water treatment. Indian J. Env. Prot. 1999,19( 6) 451 - 455.

[11] J. P. Surther land, G.K. Folkard, W.D. Grant, Natural coagulants for appropriate water treatment - a novel approach, Water lines, 8 (4), $1990,30-32$.

[12] C. Qin, H. Li, Q. Xiao, Y. Liu, J. Zhu, Y. DU, Water - Solubility of Chitosan and its antimicro bial activity. Carbohydrate polymers, 63,2006, $367-374$.

[13] M.V. Smoluchowski, Versucheiner Mathematischen, Theorie der koagulations kinetic kolloider Lousungen. Z. Phys. Chem. 92,1917, $129-168$.

[14] D. A. Fridklisberg, A course in colloid chemistry, Mir Publishers Moscow, Russia, 1984,266 - 268.

[15] D. K. Danov, P. A. Kralchevsky, I.B. Ivanov, Dynamic process in surfactants stabilized Emulsion, Faculty of Chemistry, University of Sofia,2001.

[16] R. J. Hunter, Introduction to Modern Science, Oxford University Press, New York, 1993, 33 - 38.

[17] M.C Menkiti, P. C. Nnaji Ci. I. Nwoye, O.D. Onukwuli, Coagulation Kinetics and Functional Parameters Responses of Mucana Seed Coagulant to $\mathrm{pH}$ Variation in Organic Rich Coal Effluence Medium, Journal of Minerals \& Materials Characterization \& Engineering, 9(2) 2010, $89-103$.

[18] AWWA, American Water Works Association, standard methods for the examination of water and waste water effluent, New York, 2005, USA.

[19] R. Sanghi, B. Bhattacharya, Comparative Evaluation of Natural polyelectrolytes psyllium and chitosan as coagulant Aids for Decolourization of Dye Solutions. Water Qual. Res. J. Canada, 40(1), 2005, 97 - 101

[20] M.C. Menkiti, C.A. Onyechi, D.O. Onukwuli, 2011. Evaluation of perikinetics compliance for the coag-flocculation of Brewery Effluent by Branchystegia enrycoma seed Extract. International Journal of Multi disciplinary sciences and Engineering, 2(6),2011, 73 -80 .

[21] A. L. Ahmed, S. Sumath, B.H. Hameed, "Coagulation of Residue Oil Mill Effluent by Chitosan, Ahim and PAC". Chemical Engineering Journal, 118,2006, $99-105$.

[22] A. Ariffin, R.S.A. Shatat, N.A.R. Nik, O.A.K. Mohd, "Synthetic Polyelectrolytes of Varying Charge Densities but Similar Molar Mass based on Acrylamide and their Applications on palm oil Mill Effluent Treatment". Desalination. 173,2005, 201 - 208

[23] H. Holthoff, S.U. Egelhaaf, M. Brokovec, P. Shurtenberger, H. Sticher, Coagulation rate Measurement of colloidal particles by simultaneous static and Dynamic Light Scattering. Journal of American Chemical Society. 12, 1996,5541-5549.

[24] W. Nowicki, G. Nowicka, Koagulation Kinetics, A Laboratory Experiment. J. Chem. Educ., 68,1991, 523.

[25] J.H. Van Zanten, M. Elimelech, Determination of Rate constants by multi angle light seathering, Journal of Colloid and Interface, 154 $(1), 1992,621$. 